\title{
Chronic intermittent hypobaric hypoxia improves markers of iron metabolism in a model of dietary-induced obesity
}

\author{
Fang Cui ${ }^{1,2 \dagger}$, Jing Guo ${ }^{1 \dagger}$, Hao-Fei Hu${ }^{1}$, Yi Zhang $^{3}$ and Min Shi ${ }^{1^{*}}$
}

\begin{abstract}
Background: Obesity, a risk factor for many chronic diseases, is a potential independent risk factor for iron deficiency. Evidence has shown that chronic intermittent hypobaric hypoxia $(\mathrm{ClHH})$ has protective or improved effects on cardiovascular, nervous, metabolic and immune systems. We hypothesized that $\mathrm{ClHH}$ may ameliorate the abnormal iron metabolism in obesity. This study was aimed to investigate the effect and the underlying mechanisms of $\mathrm{ClHH}$ on iron metabolism in high-fat-high-fructose-induced obese rats.

Methods: Six to seven weeks old male Sprague-Dawley rats were fed with different diet for 16 weeks, and according to body weight divided into four groups: control (CON), $\mathrm{ClHH}$ (28-day, 6-h daily hypobaric hypoxia treatment simulating an altitude of $5000 \mathrm{~m}$ ), dietary-induced obesity (DIO; induced by high fat diet and 10\% fructose water feeding), and $\mathrm{DIO}+\mathrm{CHH}$ groups. The body weight, systolic arterial pressure (SAP), Lee index, fat coefficient, blood lipids, blood routine, iron metabolism parameters, interleukin6 (IL-6) and erythropoietin (Epo) were measured. The morphological changes of the liver, kidney and spleen were examined. Additionally, hepcidin mRNA expression in liver was analyzed.
\end{abstract}

Results: The DIO rats displayed obesity, increased SAP, lipids metabolism disorders, damaged morphology of liver, kidney and spleen, disturbed iron metabolism, increased IL-6 level and hepcidin mRNA expression, and decreased Epo compared to CON rats. But all the aforementioned abnormalities in $\mathrm{DIO}$ rats were improved in $\mathrm{DIO}+\mathrm{ClHH}$ rats.

Conclusions: $\mathrm{ClHH}$ improves iron metabolism disorder in obese rats possibly through the down-regulation of hepcidin by decreasing IL-6 and increasing Epo.

Keywords: Chronic intermittent hypobaric hypoxia, Obesity, Iron metabolism, Hepcidin, Erythropoietin

\section{Background}

At present, the incidence of obesity is gradually increasing. Obesity is a risk factor for many chronic diseases, such as hypertension, diabetes, chronic kidney disease and many types of cancer. In recent years, it has been reported that obesity is associated with abnormal iron metabolism [1], and obese people are more prone to iron

\footnotetext{
* Correspondence: sm8344@sina.com

${ }^{\dagger}$ Fang Cui and Jing Guo contributed equally to this work.

'Department of Clinical Laboratory, The Second Hospital of Hebei Medical University, Shijiazhuang 050000, PR China

Full list of author information is available at the end of the article
}

deficiency (ID) and iron deficiency anemia (IDA) than normal people [2-4]. An estimated 800,000 deaths worldwide are attributed to ID. IDA can lead to fatigue, motor dysfunction, hypothermia, mental retardation, and decreased immunity [1], which is a risk factor for heart failure and increasing mortality. Therefore, the prevention and treatment of obesity and the corresponding ID has very important clinical significance.

Hepcidin regulate the release of cellular iron and body iron homeostasis $[5,6]$, which is regulated by iron level, inflammation, erythropoietin (Epo) and hypoxia $[7,8]$. 
Recent studies have shown that obesity, a chronic low inflammation state [9-11], upregulates inflammatory cytokine such as interleukin6 (IL-6), then promotes the expression of hepcidin by activating the Janus kinase signal transducer and activator of transcription-3 (JAK2STAT3) signal pathway [12, 13] . It has also been confirmed that Epo downregulates hepcidin through the transcription factor CCAAT enhancer binding protein alpha (CEBPA) and homologous DNA binding to the hepcidin promoter binding site [14].

Accumulating evidence has demonstrated the benefits of chronic intermittent hypobaric hypoxia $(\mathrm{CIHH})$ on multiple organs of the body such as heart, brain, liver, and kidney [15-18], including regulating immune system, anti-collagen-induced arthritis [19], antihypertensive activity [15], and improving dyslipidemia and glucose tolerance in type 2 diabetes [16] . Recently, it was reported that $\mathrm{CIHH}$ had an anti- aplastic anemia eect through improving the adhesiveness and stress of mesenchymal stem cells [20], and a modulating effect on brain iron homeostasis in rats [18] . Accordingly we proposed the hypothesis that $\mathrm{CIHH}$ may ameliorate the abnormal iron metabolism in obesity. In this study, we aimed to investigate the effect and the underlying mechanisms of $\mathrm{CIHH}$ on iron metabolism in dietary-induced obesity (DIO) rats.

\section{Materials and methods}

\section{Animals model establishment and $\mathrm{CIHH}$ treatment}

Six to seven weeks old male Sprague-Dawley rats (body weight $80-120 \mathrm{~g}$ ) provided by the Animal Center of Hebei Medical University were randomly divided into chow diet and high-fat-high-fructose diet groups, which were fed with a chow diet and drinking water (containing $22 \%$ protein, $4 \%$ fat, and $50 \%$ carbohydrate; nutrient ratio, specific composition per $1000 \mathrm{~g}: 99.50 \mathrm{~g}$ water, $216.97 \mathrm{~g}$ protein, $50.38 \mathrm{~g}$ fat, $56.87 \mathrm{~g}$ coarse ash, $24.00 \mathrm{~g}$ fiber, $13.29 \mathrm{~g}$ calcium, $9.17 \mathrm{~g}$ phosphorus) and with a high-fat diet and fructose water (containing $24 \%$ protein, $12 \%$ fat, and $42 \%$ carbohydrate; nutrient ratio, specific composition: $8 \%$ lard, $2 \%$ soy flour and $90 \%$ chow diet. $10 \%$ (wt/vol) fructose in water) [21], respectively.

After feeding for 16 weeks with different diet, the fat model was established with the following indicator: (Body weight of high-fat-high-fructose diet rat - average body weight of chow diet rat) $\times 100 \%$ / average body weight of chow diet rat $\geq 20 \%$ [22]. Rats were discarded from experiment if their body weight did not reach this threshold. A total of 24 rats were selected and divided into four groups, namely the control $(\mathrm{CON})$, chronic intermittent hypobaric hypoxia treatment $(\mathrm{CIHH})$, dietary induced obesity (DIO), and DIO plus $\mathrm{CIHH}$ treatment $(\mathrm{DIO}+\mathrm{CIHH})$ group. During the 4 weeks of $\mathrm{CIHH}$ treatment (from 17 to 20 week), the rats from the $\mathrm{CIHH}$ and $\mathrm{DIO}+\mathrm{CIHH}$ groups were treated $6 \mathrm{~h}$ daily under hypobaric hypoxic conditions simulating an altitude of $5000 \mathrm{~m}$, for 28 days in a hypobaric chamber. The remainder of the time the rats were in a normoxic environment. The rats from the $\mathrm{CON}$ and DIO groups were always kept under normoxic conditions. All animals were housed in a temperature-controlled room (22 \pm $1{ }^{\circ} \mathrm{C}$ ) with a $12 \mathrm{~h} / 12 \mathrm{~h}$ light/dark cycle, had ad libitum access to food and water, and diet was as usual. During the experiment, body weight and systolic arterial pressure (SAP) were measured at a fixed time every week using a Panlab model LE5001 tail-cuff pressure meter (Harvard Apparatus, Barcelona, Spain).

All the experiments were conducted in compliance with the Guide for the Care and Use of Laboratory Animals (National Research Council 2006), which were reviewed and approved by the Ethics Committee for the Use of Experimental Animals of Hebei Medical University.

\section{Adipose analysis}

At the end of the experiments, rats were fasted overnight and euthanized with a sodium pentobarbital overdose $(50 \mathrm{mg} / \mathrm{kg}$, intraperitoneal). Body weight and length were measured to calculate the Lee index (body weight $x$ $1000^{1 / 3} /$ length) [23]. Mesenteric, epididymal, and perirenal fats were collected and weighted to derive the fat coefficient (\%; (fat weight/body weight) $\times 100 \%$ ).

\section{Blood routine and blood biochemical assay}

After the rats were euthanized, 8-ml blood samples were collected from the inferior vena cava of the rats and centrifuged at $3500 \mathrm{rpm}$ for $10 \mathrm{~min}$ to obtain serum for assay. The levels of red blood cells (RBCs) and hemoglobin $(\mathrm{Hb})$ were measured with a blood cell analyzer (XS-500i Blood Cell Analyzer; Sysmex, Kobe, Japan). The levels of total cholesterol (TC), triglyceride (TG), high density lipoprotein cholesterol (HDL) and low density lipoprotein cholesterol (LDL) were measured by Colorimetric method. The levels of rat IL-6, Epo and serum ferritin (SF) were measured by ELISA kits (Shanghai Enzyme-linked Biotechnology Co., Ltd., Shanghai, China). The levels of serum iron (SI) and total iron binding capacity (TIBC) were measured by spectrophotometry, and transferrin saturation (TS\%) was calculated as SI / TIBC $\times 100 \%$. Enzymelinked immunosorbent assay (ELISA) was performed to determine the level of IL-6 and Epo according to the instructions of the kit (Shanghai Enzyme-linked Biotechnology Co., Ltd., Shanghai, China), briefly, the serum reacts with the antibody, then absorbance value is detected with a microplate reader at a wavelength of $450 \mathrm{~nm}$ followed by the calculation and statistical analysis of concentration from the standard curve. 


\section{Hematoxylin-eosin (HE) staining}

Small pieces $\left(1 \mathrm{~cm}^{3}\right)$ of liver, kidney and spleen were fixed in $4 \%$ paraformaldehyde for $24 \mathrm{~h}$, dehydrated in gradient ethanol step by step, embedded in paraffin, cut into 5- $\mu \mathrm{m}$ thick sections, stained with HE, and then observed under an Olympus BX50 optical microscope (Olympus Optical, Tokyo, Japan). The morphological changes in two sections from each rat, 6 rats in each group were evaluated [19].

\section{qRT-PCR analysis}

Rat liver total RNA was isolated with the RNA extraction kit from Omega Bio-Tek (Norcross, GA, USA), and first-strand cDNA was synthesized using $1 \mathrm{mg}$ total RNA (DNase-treated) using the I script cDNA synthesis kit for reverse transcription purchased from Nanjing Nuoweizan Biotechnology Co., Ltd. (Nanjing, China). qRT-PCR gene expression analysis was performed with the kit for qRT-PCR Master Mix purchased from ABI (Waltham, MA, USA). $\beta$-actin was used as an internal control. Primers (Sangong Biotech, Shanghai, China) designed for qRT-PCR gene expression analysis were listed in Table 1. The relative expression of each gene was calculated from $2^{-\Delta \Delta C T}$. All values were normalized to the levels of $\beta$-actin and expressed as relative mRNA level compared to the average level of the CON group.

\section{Data analyses}

Data are expressed as the mean \pm standard deviation (SD), $\mathrm{n}$ represents the number of animals in each experiment. Statistical analysis was conducted using one-way analysis of variance (ANOVA) followed by a Student-Newman Keuls's post hoc test for comparison among multiple groups using the statistical analysis Software Prism 5.0 (Graphpad Software, Inc., La Jolla, CA, USA). A value of $P<0.05$ was considered statistically significant.

\section{Results}

\section{Effect of ClHH on body weight and SAP}

During the 16-week period for the development of the obesity model, the body weight of all rats increased steadily $(P<0.01$; Fig. 1a). After 16 weeks, the body weight of the rats fed with the high-fat-high-fructose diet was heavier than those with the chow diet $(320.92 \pm$ 19.69 vs. $388.92 \pm 8.24$, exceeded $20 \%, P<0.01$; Fig. $1 \mathrm{a}$, b). Even though the diet and water intakes were not different among four groups of rats during the $\mathrm{CIHH}$ treatment (data no supply), the body weight of the rats in the $\mathrm{DIO}+\mathrm{CIHH}$ group was decreased compared with the rats in the DIO group after 4 weeks of $\mathrm{CIHH}$ treatment $(P<0.05$; Fig. $1 b)$.

Before the CIHH treatment, the SAP was higher in $\mathrm{DIO}$ and $\mathrm{DIO}+\mathrm{CIHH}$ rats than that in $\mathrm{CON}$ and $\mathrm{CIHH}$ rats $(P<0.01)$. After 4 weeks of $\mathrm{CIHH}$ treatment, the SAP was decreased in $\mathrm{DIO}+\mathrm{CIHH}$ rats compared with DIO rats $(P<0.05$; Fig. 1 c $)$.

\section{Effect of ClHH on obesity parameters}

The Lee index and fat coefficient, an index for the visceral fat content and obesity, similar to human's Body Mass Index, were significantly increased in DIO rats compared with $\mathrm{CON}$ rats $(3.18 \pm 0.04$ vs. $2.93 \pm 0.09$ and $4.23 \pm 0.52 \%$ vs. $1.44 \pm 0.26 \%$, respectively, $P<0.01$ ), and were decreased in $\mathrm{DIO}+\mathrm{CIHH}$ rats compared with $\mathrm{DIO}$ rats $(3.02 \pm 0.03$ vs. $3.18 \pm 0.04$ and $2.87 \pm 0.36 \%$ vs. $4.23 \pm 0.52 \%$, respectively, $P<0.01$; Fig. 1 d, e).

\section{Effect of $\mathrm{ClHH}$ on blood biochemical parameters Blood lipids}

Compared with CON rats, TC, TG and LDL were significantly increased in DIO rats $(P<0.01)$, whereas $\mathrm{TC}$ were decreased in $\mathrm{DIO}+\mathrm{CIHH}$ rats compared with DIO rats $(P<0.01)$, although there were no differences in TG and LDL between $\mathrm{DIO}+\mathrm{CIHH}$ and DIO rats $(P>0.05)$. There were no differences in HDL among four groups (Fig. 2).

\section{Blood routine and iron metabolism parameters}

$\mathrm{RBCs}, \mathrm{Hb}$ and SF levels were decreased in DIO rats compared with those in CON rats $(P<0.05)$ and increased in $\mathrm{DIO}+\mathrm{CIHH}$ rats compared with those in DIO rats $(P<0.05$; Figs. 3 and 4$)$. The TIBC level was increased in DIO rats compared with that in $\mathrm{CON}$ rats $(P<0.01)$, although there was lower in $\mathrm{DIO}+\mathrm{CIHH}$ group than DIO group, no statistical difference $(P=$ $0.592, P>0.05$; Fig. 4). There was no difference in the SI level between four groups ( $P=0.136$; Fig. 4).

\section{Level of inflammatory factor}

Serum IL-6 level, typical inflammatory factor, was increased in DIO rats compared with CON rats $(P<0.01)$ and decreased in $\mathrm{DIO}+\mathrm{CIHH}$ rats compared with DIO rats $(P<0.01$; Fig. 5$)$.

Table 1 Sequence of primers and annealing temperature

\begin{tabular}{lll}
\hline Gene & Primer sequence & Annealing temperature \\
\hline Hepcidin & F 5'- AGATGGCACTAAGCACTCGG $-3^{\prime}$ & $56^{\circ} \mathrm{C}$ \\
& R 5'- ATCAGCAGCGCACTGTCATC - 3' & \\
$\beta$-actin & F 5'- GAAATCGTGCGTGACATTAAAGAG - 3' & $56^{\circ} \mathrm{C}$ \\
& R 5'- GCGGCAGTGGCCATCTC - 3' & \\
\hline
\end{tabular}




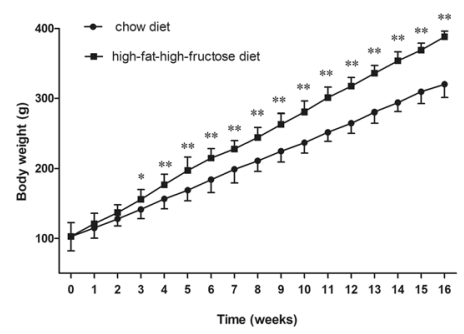

A

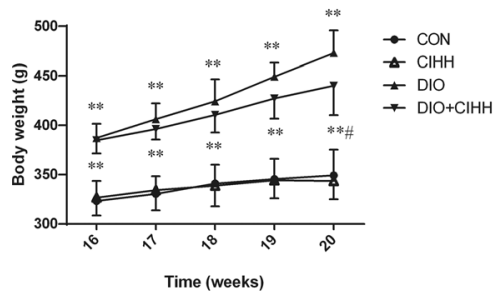

B

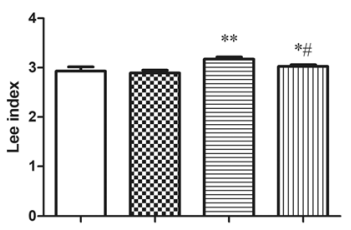

D

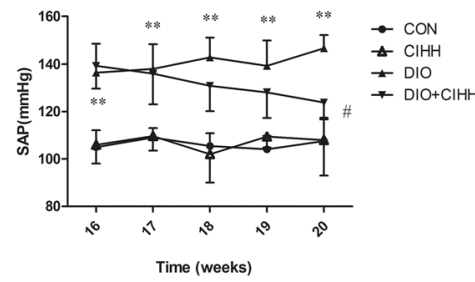

C

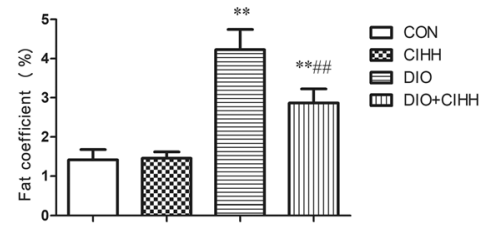

E

Fig. 1 The effect of $\mathrm{ClHH}$ on body weight, systolic arterial pressure (SAP) and obesity parameters in rats during $\mathrm{ClHH}$ treatment. a and $\mathbf{b}$ Body weight; c SAP; d Lee index (body weight $\times 1000^{1 / 3} /$ length); e Fat coefficient (\%; (fat weight/body weight) $\times 100 \%$ ). CON: control group, ClHH: $\mathrm{ClHH}$ group, $\mathrm{DIO}$ : dietary-induced obesity group, $\mathrm{DIO}+\mathrm{CIHH}$ : $\mathrm{DIO}+\mathrm{ClHH}$ group. All data are expressed as the mean $\pm \mathrm{SD} ; n=5-6$ for each group. ${ }^{*} P<0.05{ }^{* *} P<0.01$ vs. CON, ${ }^{\#} P<0.05{ }^{\# \#} P<0.01$ vs. DIO

\section{Level of Epo}

The Epo level was decreased in DIO rats compared with $\mathrm{CON}$ rats $(P<0.01)$ and increased in $\mathrm{DIO}+\mathrm{CIHH}$ rats compared with DIO rats $(P<0.05$; Fig. 6$)$.

\section{Effect of $\mathrm{CIHH}$ on the histology of liver, kidney and spleen} Histological analysis of liver

Significant hepatic steatosis was found in DIO rats, along with irregular hepatic cord arrangement. The pathological changes were substantially alleviated in $\mathrm{DIO}+$ CIHH rats (Fig. 7a).

\section{Histological analysis of kidney}

Mild hydropic degeneration of renal tubular epithelial cells was found in DIO rats. The pathological changes were considerably alleviated in $\mathrm{DIO}+\mathrm{CIHH}$ rats (Fig. $7 \mathrm{~b}$ ).

\section{Histological analysis of spleen}

The splenic nodules were significantly increased in DIO rats, together with the grown lymphoid tissue. The pathological changes were greatly alleviated in $\mathrm{DIO}+$ CIHH rats (Fig. 7c).

\section{Effect of $\mathrm{ClHH}$ on the relative mRNA expression of hepcidin}

The relative mRNA expression of hepcidin was increased in the liver of DIO rats compared with that in CON rats $(P<0.01)$, and was downregulated in the liver of $\mathrm{DIO}+\mathrm{CIHH}$ rats compared with that in DIO rats $(P<0.05$; Fig. 8).

\section{Discussion}

In this study, DIO rats exhibited obesity, increased SAP, lipids metabolism disorders, morphological damage of the liver, spleen and kidney, lower levels of RBCs and $\mathrm{Hb}$, and iron metabolic disturbance. Additionally, DIO rats also had increased levels of IL-6 and hepcidin, and decreased Epo level. As we expected, all changes in DIO rats were alleviated by the $\mathrm{CIHH}$, which suggests that $\mathrm{CIHH}$ improved iron metabolic disturbance in DIO rats. 


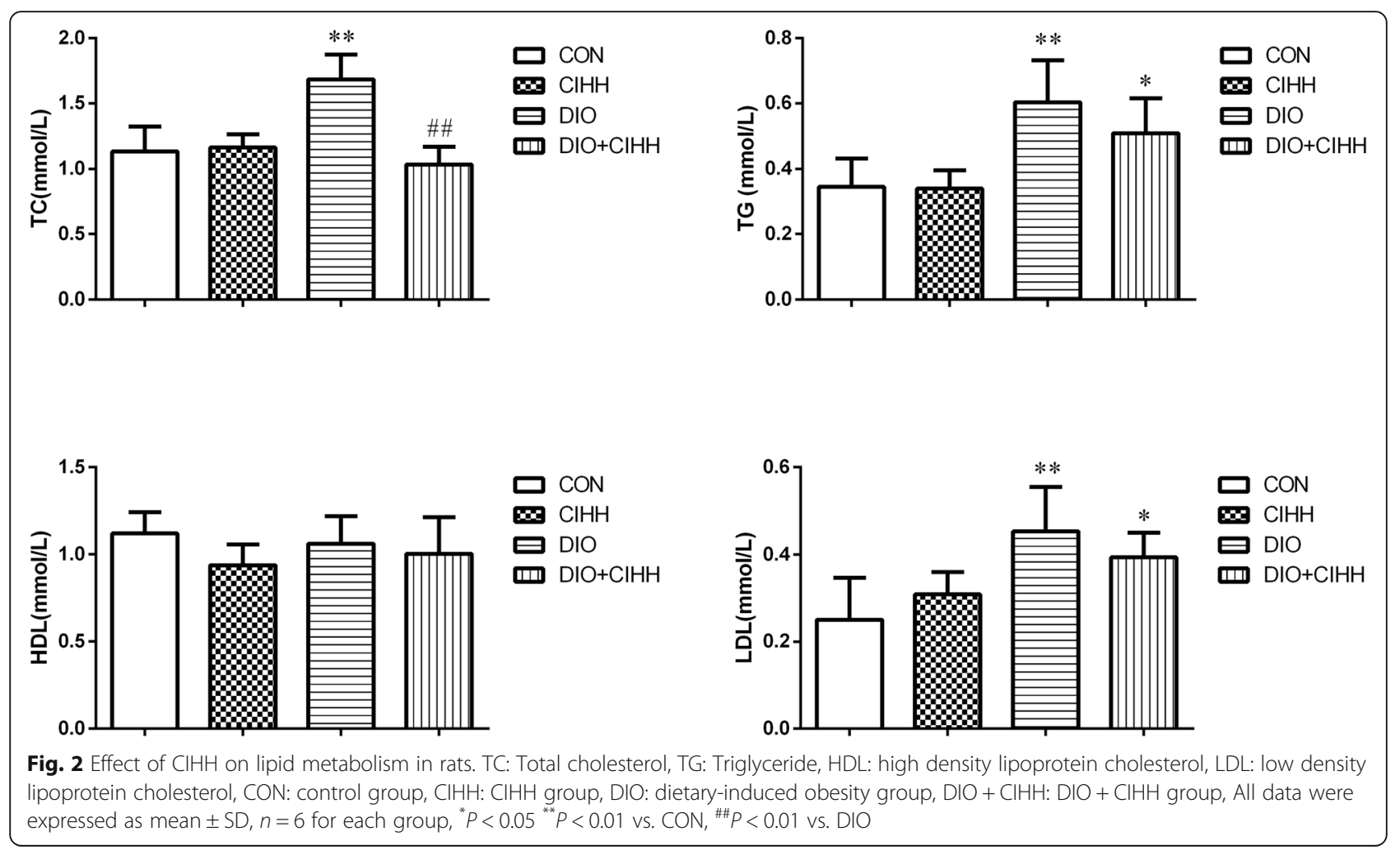

This improvement might be related to the downregulation hepcidin by decreasing IL-6 and increasing Epo.

Iron is an important trace element that plays a vital role in the transport of oxygen and in erythropoiesis. The imbalance of iron can lead to ID or iron overload [24]. ID initially manifests as iron depletion, then as iron-deficient RBCs, which ultimately leads to IDA $[25,26]$. Currently, the commonly used indices to evaluate iron status in the body include RBCs parameters (Hb, RBC count), SF, SI, serum transferrin receptor (sTfR), and TIBC. It has been reported that obesity is often accompanied by abnormalities in iron metabolism, but the results were not completely conclusive. For example, Abo Zeid et al. reported that the levels of SI,
TIBC and TS\% were lower and SF was higher in obese rats [27]. Khan et al. found a significant decrease in SI and an increase in SF in obese people [28]. Additionally, some researchers reported that both SI and SF were lower in obese rats [29], CIHH had a regulatory effect on brain iron balance, and exerted neuroprotective effects by reducing brain iron content in rats [18]. In this study, we found that there was a significant decrease in $\mathrm{Hb}, \mathrm{RBC}$ count, $\mathrm{SI}$ and $\mathrm{SF}$, but an increase in TIBC in the DIO rats, while an increase in $\mathrm{CIHH}$-treated DIO rats. These results indicate that DIO rats had an abnormal iron metabolism with potential risk of ID, while $\mathrm{CIHH}$ had a regulatory effect against abnormal iron metabolism in obese rats.

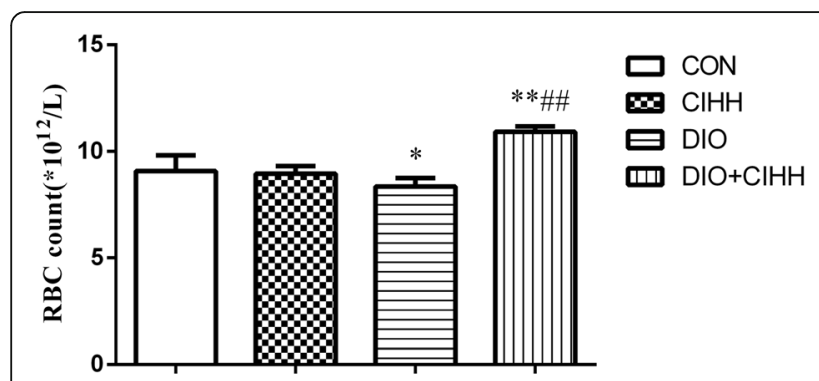

A

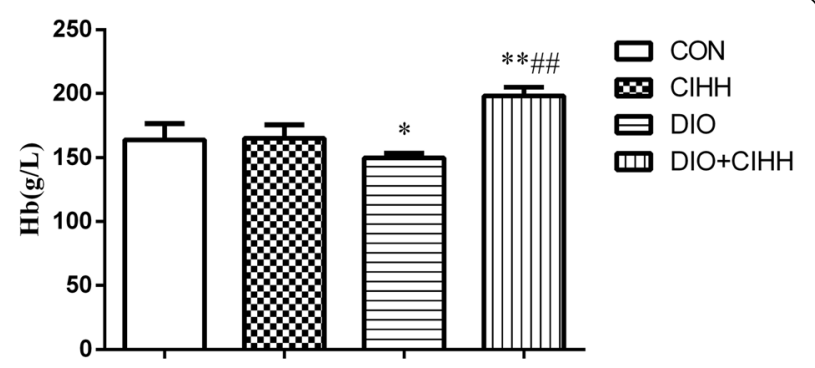

B

Fig. 3 The effect of $\mathrm{ClHH}$ on red blood cell and hemoglobin $(\mathrm{Hb})$ in rats. a The effect of $\mathrm{ClHH}$ on red blood cell (RBC); $\mathbf{b}$ The effect of $\mathrm{ClHH}$ on $\mathrm{Hb}$. CON: control group, $\mathrm{ClHH}$ : $\mathrm{ClHH}$ group, $\mathrm{DIO}$ : dietary-induced obesity group, $\mathrm{DIO}+\mathrm{ClHH}: \mathrm{DIO}+\mathrm{ClHH}$ group. All data are expressed as the mean $\pm S D ; n=6$ for each group. ${ }^{*} P<0.05^{* *} P<0.01$ vs. CON, ${ }^{\# \#} P<0.01$ vs. DIO 


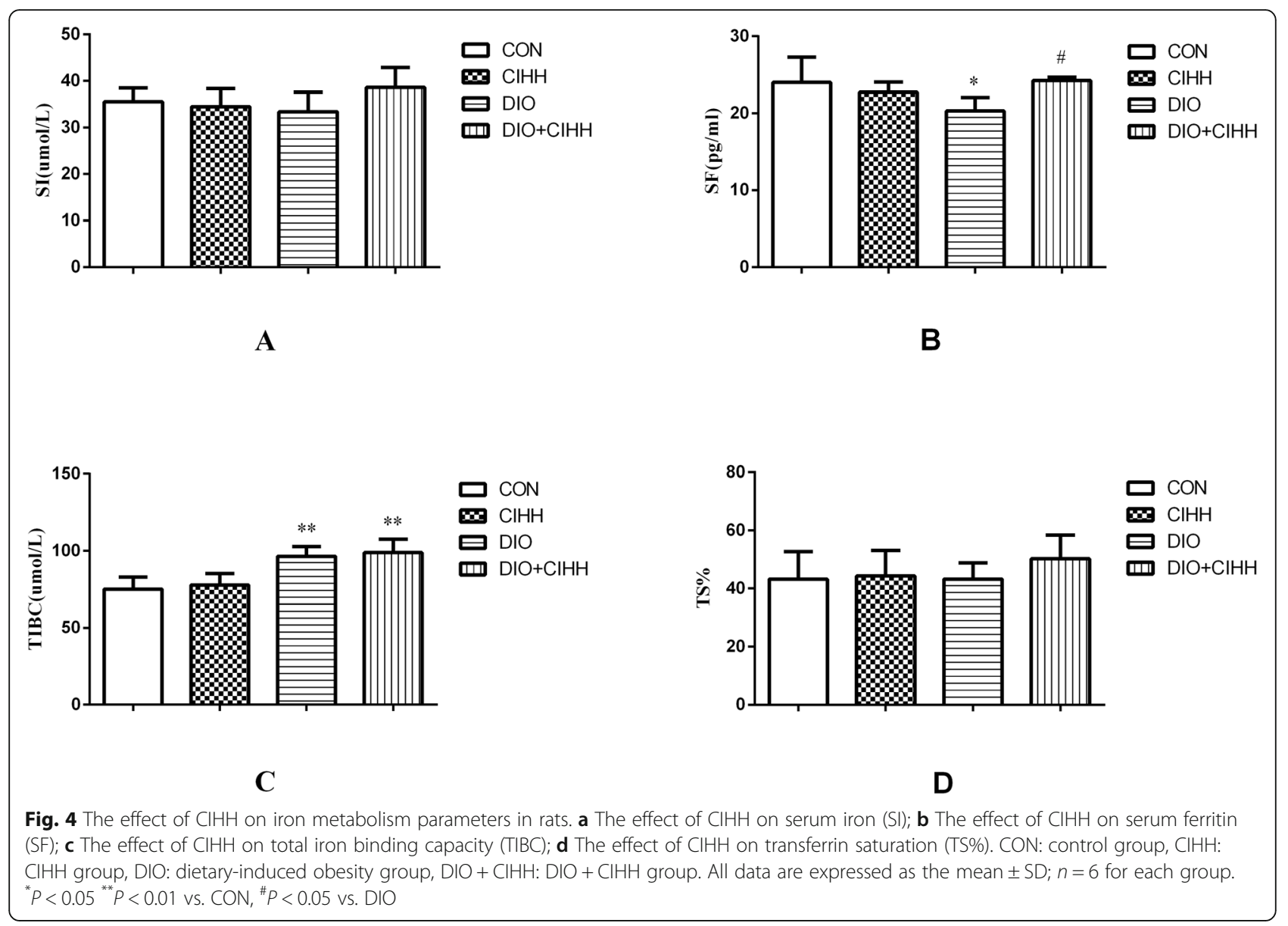

It is well known that hepcidin is a key regulator of iron homeostasis and in the pathogenesis of anemia [30]:Hepcidin regulates plasma iron balance by inhibiting intestinal iron absorption and macrophage iron release [6, 31, 32]. The expression of hepcidin can be induced by inflammation and iron overload, but inhibited by Epo, iron deficiency and hypoxia $[7,8]$. Research has confirmed that IL-6 is increased in obesity, a low chronic inflammatory state, and could decrease serum iron level by inducing the expression of hepcidin and downregulating SI via the JAK2-STAT3 signal pathway $[12,13]$. It was also reported that moderate normobaric hypoxia could reduce the

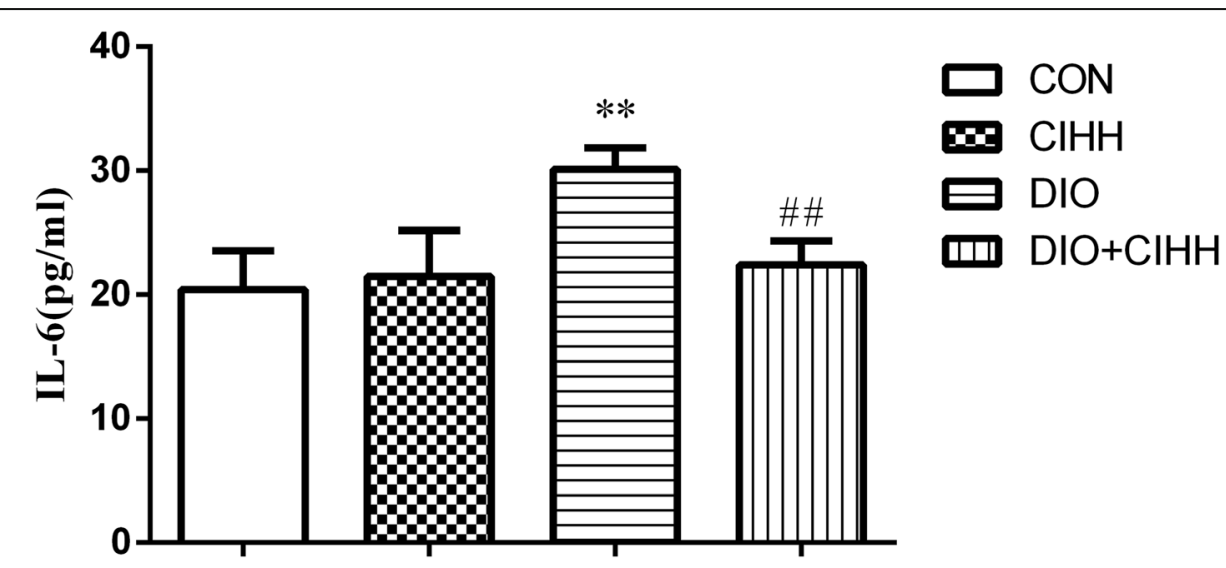

Fig. 5 Effect of $\mathrm{ClHH}$ on serum inflammatory cytokines IL-6 in rats. CON: control group, $\mathrm{ClHH}$ : CIHH group, DIO: dietary-induced obesity group, $\mathrm{DIO}+\mathrm{ClHH}: \mathrm{DIO}+\mathrm{ClHH}$ group. All data are expressed as the mean $\pm \mathrm{SD} ; n=6$ for each group. ${ }^{* *} P<0.01 \mathrm{vs}$. CON, ${ }^{\# \#} P<0.01 \mathrm{vs}$. DIO 


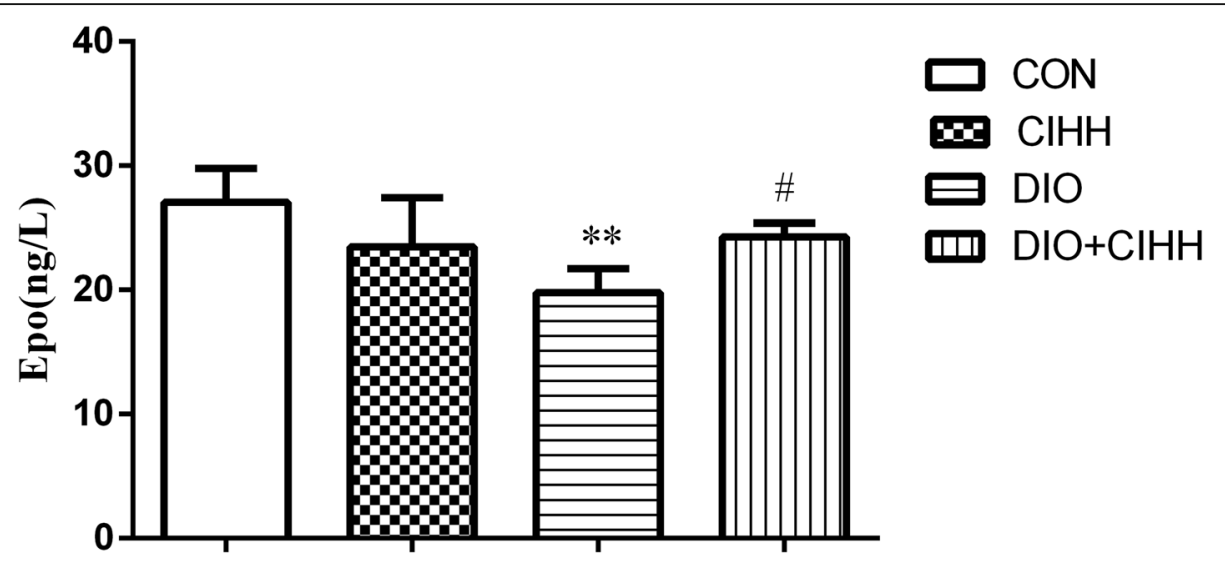

Fig. 6 Effect of $\mathrm{ClHH}$ on serum erythropoietin in rats. CON: control group, $\mathrm{ClHH}$ : $\mathrm{ClHH}$ group, DIO: dietary-induced obesity group, $\mathrm{DIO}+\mathrm{CIHH}$ : $\mathrm{DIO}+\mathrm{ClHH}$ group. All data are expressed as the mean $\pm \mathrm{SD} ; n=6$ for each group. ${ }^{* *} P<0.01$ vs. CON, ${ }^{\#} P<0.05$ vs. DIO

inflammatory response and the secretion of liver hepcidin, promote intestinal iron absorption, improve the iron homeostasis, and prevent iron deficiency in athletes [33]. The results of this study showed that there was no significant change in liver hepcidin mRNA expression level in the $\mathrm{CIHH}$ group, which may be related to the timing of the day and duration of the hypoxia treatment in the animals. In comparison, our results showed the expression of hepcidin mRNA in obese rats was significantly upregulated and the level of serum IL-6 was increased in DIO rats, and the change in hepcidin and IL-6 expression was effectively improved in CIHH-treated DIO rats. Thus, it can be speculated that $\mathrm{CIHH}$ improves inflammation and abnormal iron metabolism by inhibiting IL-6-activation and hepcidin in obese rats.

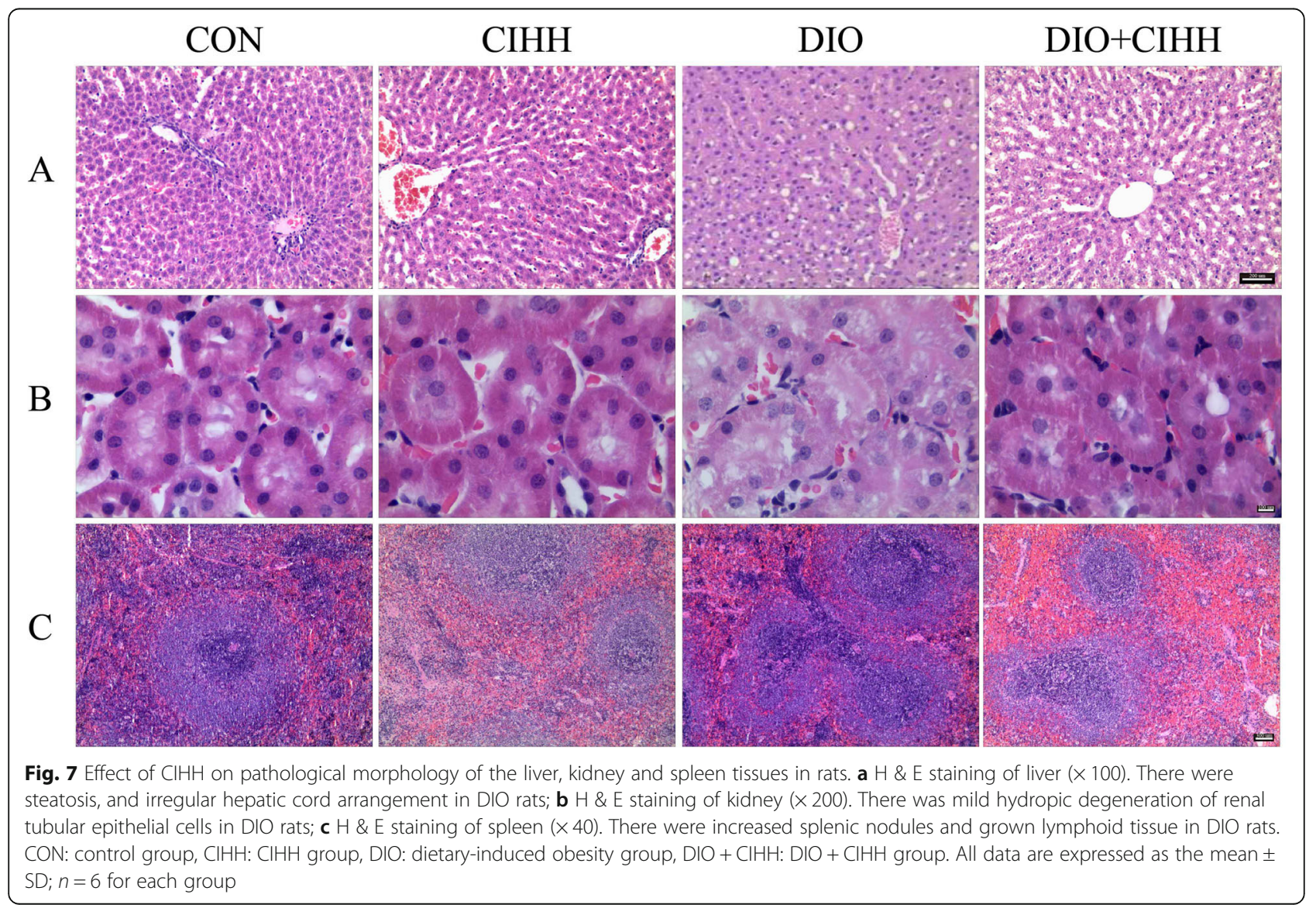




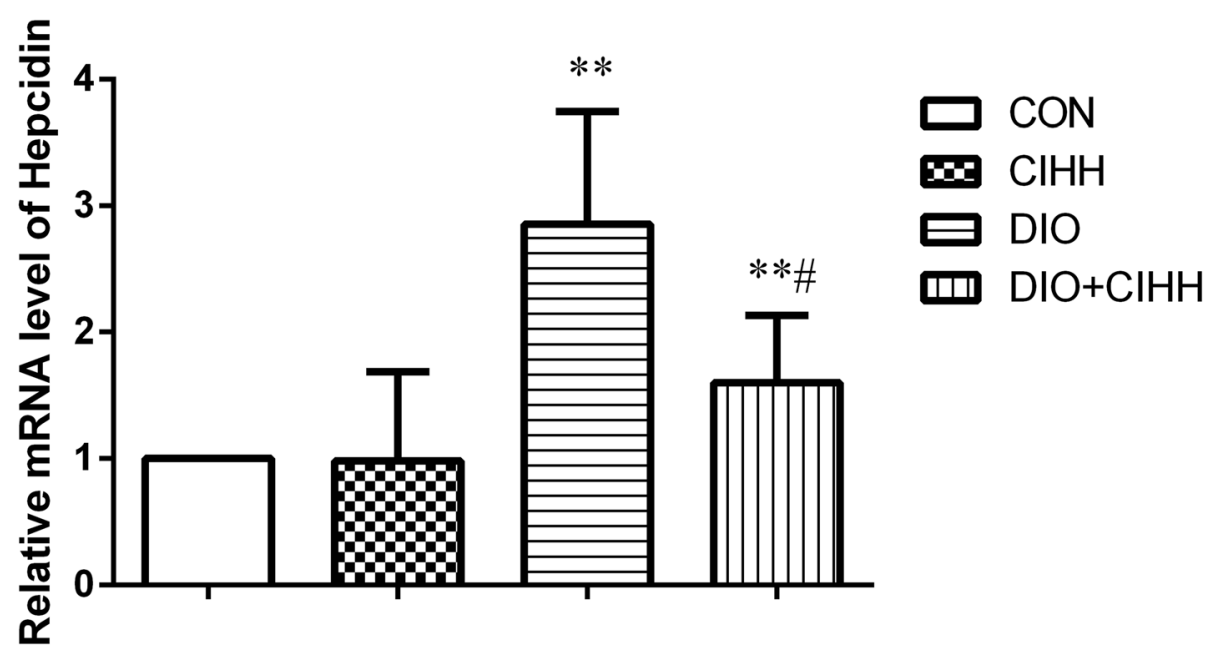

Fig. 8 Effect of $\mathrm{ClHH}$ on the relative mRNA expression of hepcidin in the liver of rats. CON: control group, $\mathrm{ClHH}$ : CIHH group, DIO: dietaryinduced obesity group, $\mathrm{DIO}+\mathrm{ClHH}: \mathrm{DIO}+\mathrm{ClHH}$ group. All data are expressed as the mean $\pm \mathrm{SD} ; n=6$ for each group. ${ }^{* *} P<0.01 \mathrm{vs}$. CON, ${ }^{\#} P<0.05$ vs. DIO

Epo, which is secreted by kidney, regulates the growth of erythroid progenitor cells, and promotes the proliferation of red blood cells and synthesis of Hb. Accordingly, it is considered as another important hepcidin regulator [34]. It has also been confirmed that Epo downregulates hepcidin through the transcription factor CCAAT enhancer binding protein alpha (CEBPA) and homologous DNA binding to the hepcidin promoter binding site [14] . Our previous studies demonstrated that $\mathrm{CIHH}$ reduced the hematopoietic dysfunction and antagonized anemia by increasing the serum positive hematopoietic regulatory factor Epo. But it does not clarify the effects and mechanisms of $\mathrm{CIHH}$ on hepcidin and iron metabolism in obese rats [20]. In this study, we found that in obese rats the level of Epo was significantly decreased and hepcidin was increased, and $\mathrm{CIHH}$ effectively increased Epo and downregulated hepcidin. Thus, it can be speculated that $\mathrm{CIHH}$ may inhibit the expression of hepcidin by increasing Epo levels in obese rats. Although it has been reported that injection of synthetic Epo could reduce the level of the inflammatory cytokine IL-6 $[35,36]$, there are few studies on the relationship between Epo and inflammatory cytokines, and the mechanism is still unclear. Therefore, further studies are needed to establish whether Epo directly inhibits the inflammatory cytokine IL-6 or whether there is an interaction between them, so it warrants further investigation in future studies.

Some research has reported that weight loss, modified diet or physical exercise, decreased the levels of sTFR, IL-6, and hepcidin, while increased the levels of $\mathrm{Hb}$, Epo, and SI [37-39]. In this study, we found that CIHH decreased body weight in spite of no difference in the intakes of diet and water. We are not sure whether weight loss or $\mathrm{CIHH}$ treatment or both produce the same results of the iron metabolism, so it warrants further investigation in future studies.

In conclusion, our studies demonstrated for the first time that $\mathrm{CIHH}$ improves iron metabolic disturbance in obese rat through downregulation of hepcidin by inhibiting the inflammatory cytokine IL-6 and promoting Epo expression, which implied that $\mathrm{CIHH}$ had a regulatory effect on iron balance and exerted protective effects on iron metabolic disturbance of obese rat. Exposure to intermittent hypoxia as a training or treatment method for sports and cardiovascular diseases has been reported decades ago, and has been proved having lots of beneficial action such as losing of body mass and improving metabolic abnormality, decreasing hepatic hepcidin expression and increasing availability of circulating iron that can be used for erythropoiesis [40, 41]. With optimal level and time, $\mathrm{CIHH}$ may be promising to become a potential therapy for prevention and treatment of iron metabolic disturbance and ID in anemia patients.

\section{Abbreviations}

$\mathrm{CIHH}$ : Chronic intermittent hypobaric hypoxia; DIO: Dietary-induced obesity; CON: Control group; SAP: Systolic arterial pressure; RBCs: Red blood cells;

TC: Total cholesterol; TG: Triglyceride; HDL: High density lipoprotein cholesterol; LDL: Low density lipoprotein cholesterol; SI: Serum iron; SF: Serum ferritin; TS\%: Transferrin saturation; TIBC: Total iron binding capacity; IL-6: Interleukin-6; Epo: Erythropoietin; ID: Iron deficiency; IDA: Iron deficiency anemia; Hb: Hemoglobin; ELISA: Enzyme-linked Immune Sorbent Assay; qRT-PCR: Quantitative Real-Time Polymerase Chain Reaction; HE: Hematoxylin and eosin

\section{Acknowledgements} Not applicable.

\section{Authors' contributions}

F.C., J.G., and H.F.H. performed the experiments and drafted the manuscript; Y.Z. analyzed the data; M.S. was responsible for conception and design of the research, revised and approved the final manuscript. The author(s) read and approved the final manuscript. 


\section{Funding}

This study was supported by the Hebei Province Science and Technology Plan Project (No, 16277734D), Hebei Province Medical Science Research Key Project (No, 20160114)

\section{Availability of data and materials}

All results and data are kept in the section for Department of Clinical Laboratory, The Second Hospital of Hebei Medical University, Shijiazhuang, China. These will be made available from the corresponding author on reasonable request.

\section{Ethics approval and consent to participate}

All the experiments were conducted in compliance with the Guide for the Care and Use of Laboratory Animals (National Research Council 2006), which were reviewed and approved by the Ethics Committee for the Use of Experimental Animals of Hebei Medical University.

\section{Consent for publication}

Not applicable.

\section{Competing interests}

The authors declare that they have no conflicts of interest.

\section{Author details}

${ }^{1}$ Department of Clinical Laboratory, The Second Hospital of Hebei Medical University, Shijiazhuang 050000, PR China. ${ }^{2}$ Department of Electron Microscope Laboratory Centre, Hebei Medical University, Shijiazhuang 050017, PR China. ³epartment of Physiology, Hebei Medical University, Shijiazhuang 050017, PR China.

Received: 2 January 2019 Accepted: 28 October 2020 Published online: 07 November 2020

\section{References}

1. Becker C, Orozco M, Solomons NW, Schumann K. Iron metabolism in obesity: how interaction between homoeostatic mechanisms can interfere with their original purpose. Part II: epidemiological and historic aspects of the iron/obesity interaction. J Trace Elem Med Biol. 2015;30:202-6.

2. Citelli M, Fonte-Faria T, Nascimento-Silva V, Renovato-Martins M, Silva R, Luna AS, da Silva SV, Barja-Fidalgo C. Obesity promotes alterations in Iron recycling. Nutrients. 2015;7:335-48.

3. Lecube A, Carrera A, Losada E, Hernandez C, Simo R, Mesa J. Iron deficiency in obese postmenopausal women. Obesity (Silver Spring). 2006;14:1724-30.

4. Tussing-Humphreys LM, Nemeth E, Fantuzzi G, Freels S, Guzman G, Holterman AX, Braunschweig C. Elevated systemic hepcidin and iron depletion in obese premenopausal females. Obesity (Silver Spring). 2010;18:1449-56.

5. Park CH, Valore EV, Waring AJ, Ganz T. Hepcidin, a urinary antimicrobial peptide synthesized in the liver. J Biol Chem. 2001;276:7806-10.

6. Nemeth E, Tuttle MS, Powelson J, Vaughn MB, Donovan A, Ward DM, Ganz T, Kaplan J. Hepcidin regulates cellular iron efflux by binding to ferroportin and inducing its internalization. Science. 2004;306:2090-3.

7. Nicolas G, Chauvet C, Viatte L, Danan JL, Bigard X, Devaux I, Beaumont C, Kahn A, Vaulont $\mathrm{S}$. The gene encoding the iron regulatory peptide hepcidin is regulated by anemia, hypoxia, and inflammation. J Clin Investig. 2002;110: 1037-44.

8. Nemeth E, Rivera S, Gabayan V, Keller C, Taudorf S, Pedersen BK, Ganz T. IL-6 mediates hypoferremia of inflammation by inducing the synthesis of the iron regulatory hormone hepcidin. J Clin Invest. 2004;113:1271-6.

9. Cepeda-Lopez AC, Osendarp SJ, Melse-Boonstra A, Aeberli I, GonzalezSalazar F, Feskens E, Villalpando S, Zimmermann MB. Sharply higher rates of iron deficiency in obese Mexican women and children are predicted by obesity-related inflammation rather than by differences in dietary iron intake. Am J Clin Nutr. 2011;93:975-83.

10. Grandone A, Marzuillo P, Perrone L, del Giudice EM. Iron metabolism Dysregulation and cognitive dysfunction in pediatric obesity: is there a connection? Nutrients. 2015:7:9163-70.

11. Nikonorov AA, Skalnaya MG, Tinkov AA, Skalny AV. Mutual interaction between iron homeostasis and obesity pathogenesis. J Trace Elem Med Biol. 2015;30:207-14

12. Wrighting DM, Andrews NC. Interleukin-6 induces hepcidin expression through STAT3. Blood. 2006;108:3204-9.
13. Verga Falzacappa MV, Vujic Spasic M, Kessler R, Stolte J, Hentze MW. Muckenthaler MU.STAT3 mediates hepatic hepcidin expression and its inflammatory stimulation. Blood. 2007;109:353-8.

14. Fleming MD. The regulation of hepcidin and its effects on systemic and cellular iron metabolism. Hematology Am Soc Hematol Educ Program. 2008. p. 151-8. https://doi.org/10.1182/asheducation-2008.1.151.

15. Li N, Guan Y, Zhang L, Tian Y, Zhang Y, Wang S. Depressive effects of chronic intermittent hypobaric hypoxia on renal vascular hypertension through enhancing Baroreflex. Chin J Physiol. 2016;59:210-7.

16. Tian YM, Liu Y, Wang S, Dong Y, Su T, Ma HJ, Zhang Y. Anti-diabetes effect of chronic intermittent hypobaric hypoxia through improving liver insulin resistance in diabetic rats. Life Sci. 2016;150:1-7.

17. Wang J, Wu Y, Yuan F, Liu Y, Wang X, Cao F, Zhang Y, Wang S. Chronic intermittent hypobaric hypoxia attenuates radiation induced heart damage in rats. Life Sci. 2016:160:57-63.

18. Li Y, Yu P, Chang SY, Wu Q, Yu P, Xie C, Wu W, Zhao B, Gao G, Chang YZ. Hypobaric hypoxia regulates brain Iron homeostasis in rats. J Cell Biochem. 2017;118:1596-605.

19. Shi M, Cui F, Liu AJ, Ma HJ, Cheng M, Song SX, Yuan F, Li DP, Zhang Y. The protective effects of chronic intermittent hypobaric hypoxia pretreatment against collagen-induced arthritis in rats. J Inflamm (Lond). 2015;12:23.

20. Yang J, Zhang L, Wang H, Guo Z, Liu Y, Zhang Y. Protective Effects of Chronic Intermittent Hypobaric Hypoxia Pretreatment against Aplastic Anemia through Improving the Adhesiveness and Stress of Mesenchymal Stem Cells in Rats. Stem Cells Int. 2017;2017:5706193.

21. Cui F, Guan Y, Guo J, Tian Y-M, Hu H-F, Zhang X-J, Zhang Y. Chronic intermittent hypobaric hypoxia protects vascular endothelium by ameliorating autophagy in metabolic syndrome rats. Life Sci. 2018;205:145-54.

22. Xu SJ, Sun X, Shi LX, Zhang Q, Peng NC. Detection and Analysis of Iron Metabolism Indexes in patients with simple Obesity. Chin J Modern Med. 2014;35:67-9.

23. Bernardis LL, Patterson BD. Correlation between 'Lee index' and carcass fat content in weanling and adult female rats with hypothalamic lesions. J Endocrinol. 1968:40:527-8.

24. Rybinska I, Cairo G. Mutual cross talk between Iron homeostasis and erythropoiesis. Vitam Horm. 2017;105:143-60.

25. Cook JD, Baynes RD, Skikne BS. Iron deficiency and the measurement of iron status. Nutr Res Rev. 1992:5:198-202.

26. Zhao L, Zhang X, Shen Y, Fang X, Wang Y, Wang F. Obesity and iron deficiency: a quantitative meta-analysis. Obes Rev. 2015;16:1081-93.

27. Abo Zeid AA, El Saka MH, Abdalfattah AA, Zineldeen DH. Potential factors contributing to poor iron status with obesity. Alexandria J Med. 2014;50:45-8.

28. Khan A, Khan WM, Ayub M, Humayun M, Haroon M. Ferritin is a marker of inflammation rather than Iron deficiency in overweight and obese people. J Obes. 2016;2016:1937320.

29. Park CY, Chung J, Koo KO, Kim MS, Han SN. Hepatic iron storage is related to body adiposity and hepatic inflammation. Nutr Metab (Lond). 2017;14:14.

30. Ganz T. Hepcidin, a key regulator of iron metabolism and mediator of anemia of inflammation. Blood. 2003;102:783-8.

31. Liu Q, Davidoff O, Niss K, Haase VH. Hypoxia-inducible factor regulates hepcidin via erythropoietin-induced erythropoiesis. J Clin Invest. 2012;122: 4635-44.

32. Qiao,Q,andGeng,H,Progress in the expression of iron modulin under hypoxia. Chongqing medicine. 2015;44(15):2134-6.

33. Wang HT, Li HZ, Li LZ, Wang JX, LV J, Liu YQ. Effects of hypoxia on inflammatory response and iron absorption protein in duodenum of rats after intensive exercise. Chin J Sports Med. 2013;323(04):326-80.

34. Hamalainen P, Saltevo J, Kautiainen H, Mantyselka P, Vanhala M. Erythropoietin, ferritin, haptoglobin, hemoglobin and transferrin receptor in metabolic syndrome: a case control study. Cardiovasc Diabetol. 2012; 11:116.

35. Rong R, Xijun X. Erythropoietin pretreatment suppresses inflammation by activating the PI3K/Akt signaling pathway in myocardial ischemiareperfusion injury. Exp Ther Med. 2015;10:413-8.

36. Turhan AH, Atici A, Muşlu N, Polat A, Sungur MA. Erythropoietin may attenuate lung inflammation in a rat model of meconium aspiration syndrome. Exp Lung Res. 2016:42:199-204.

37. Amato A, Santoro N, Calabro P, Grandone A, Swinkels DW, Perrone L, del Giudice EM. Effect of body mass index reduction on serum hepcidin levels and iron status in obese children. Int J Obes (Lond). 2010;34:1772-4. 
38. Gong L, Yuan F, Teng J, Li X, Zheng S, Lin L, Deng H, Ma G, Sun C, Li Y. Weight loss, inflammatory markers, and improvements of iron status in overweight and obese children. J Pediatr. 2014;164:795-800.e792.

39. Coimbra S, Catarino C, Nascimento H, Alves Al, Medeiros AF, Bronze-daRocha E, Costa E, Rocha-Pereira P, Aires L, Seabra A, et al. Physical exercise intervention at school improved hepcidin, inflammation, and iron metabolism in overweight and obese children and adolescents. Pediatr Res. 2017:82:781-8.

40. Sonnweber T, Nachbaur D, Schroll A, Nairz M, Seifert M, Demetz E, Haschka $D$, Mitterstiller AM, Kleinsasser A, Burtscher M, et al. Hypoxia induced downregulation of hepcidin is mediated by platelet derived growth factor BB. Gut. 2014;63:1951-9.

41. Kayser B, Verges S. Hypoxia, energy balance and obesity: from pathophysiological mechanisms to new treatment strategies. Obes Rev. 2013;14:579-92

\section{Publisher's Note}

Springer Nature remains neutral with regard to jurisdictional claims in published maps and institutional affiliations.

Ready to submit your research? Choose BMC and benefit from:

- fast, convenient online submission

- thorough peer review by experienced researchers in your field

- rapid publication on acceptance

- support for research data, including large and complex data types

- gold Open Access which fosters wider collaboration and increased citations

- maximum visibility for your research: over $100 \mathrm{M}$ website views per year

At BMC, research is always in progress.

Learn more biomedcentral.com/submissions 